\title{
Cervical cerclage for short cervix on transvaginal ultrasound: Review of effectiveness in preventing preterm birth
}

\author{
Kathleen Broad ${ }^{1}$, Heather Scott ${ }^{2}$ \\ ${ }^{1}$ Class of 2011, Faculty of Medicine, Dalhousie University \\ ${ }^{2}$ Department of Obstetrics and Gynecology, Dalhousie University
}

\begin{abstract}
Preterm birth remains one of the most important predictors of fetal morbidity and mortality. Measurement of cervical length by transvaginal ultrasound in the second trimester has been proposed as an effective screening tool in women at high risk of preterm birth and cervical cerclage has been used for over 50 years as a method of preventing preterm delivery related to cervical insufficiency. This review examines the evidence of the effectiveness of therapeutic cerclage following measurement of short cervix on transvaginal ultrasound in preventing preterm birth. Patient populations in which ultrasound-indicated cerclage has been demonstrated to have unique benefit were identified and implications for future research are discussed.
\end{abstract}

\section{Introduction}

$\mathrm{P}$ reterm birth remains one of the most important predictors of fetal morbidity and mortality. ${ }^{1}$ However, the incidence of preterm birth has not decreased over the years, despite improvements in maternal and prenatal care. ${ }^{2,3}$ Though the mechanisms leading to preterm birth have not been fully elucidated, preterm birth is now thought of as a syndrome initiated by a host of multifactorial mechanisms. ${ }^{4}$ A number of studies have found an association between preterm delivery and cervical shortening, ${ }^{4}$ suggesting that an intervention to attenuate cervical shortening may improve rates of preterm delivery. Two contemporary interventions that have shown varying degrees of effectiveness in preventing preterm delivery are ultrasound-indicated cerclage and vaginal progesterone. ${ }^{5}$ However, a survey of Canadian obstetrician/ gynaecologists found that there is significant uncertainty surrounding the indications for cerclage placement following the identification of short cervix on transvaginal ultrasound (TVUS). ${ }^{6}$ The following review will examine the evidence surrounding the effectiveness of therapeutic cerclage following measurement of short cervix on TVUS in preventing preterm birth and in particular, will focus on identifying patient characteristics that may modify the overall effectiveness of ultrasound-indicated cerclage.

\section{Relationship of Cervical Length and Preterm Birth}

There are a number of studies demonstrating that decreased cervical length on TVUS may be a risk factor for preterm birth. In a study of 705 women at high risk for spontaneous preterm birth, (prior spontaneous preterm birth at 14 to 35 weeks, cone biopsy, mullerian anomaly, or two or more dilation and evacuations), the risk of spontaneous preterm birth before 35 weeks was decreased by approximately $6 \%$ for each additional millimeter of cervical length measured between weeks 12 and $32 .{ }^{7}$ Indeed, a meta-analysis of clinical trials examining asymptomatic women at high risk of preterm birth found that the shorter the cervical length cut-off, the higher the positive likelihood ratio for preterm birth. $^{8}$ Specifically, the use of TVUS cervical length of $<25 \mathrm{~mm}$ at $<24$ weeks to predict preterm birth at $<35$ weeks revealed a sensitivity of $65.4 \%$, specificity of $75.5 \%$, positive predictive value of $33.0 \%$ and negative predictive value of $92 \% .{ }^{8}$ Cervical length as measured by TVUS in the second trimester has therefore been proposed to be an effective screening tool in women at high risk of preterm birth. However, for a screening tool to be useful, there must exist an effective intervention to prevent the adverse outcome in those identified as being high risk. In the case of asymptomatic women in whom a cervical length of $<25 \mathrm{~mm}$ is measured, an effective intervention to prevent preterm birth must exist for TVUS to be useful.

\section{History-Indicated vs. Ultrasound-Indicated Cerclage}

Cervical cerclage has been used for over 50 years as a method of preventing preterm delivery related to cervical insufficiency. ${ }^{9}$ Cerclage has been used prophylactically in women with historical evidence of being at high risk for preterm birth or second-trimester loss due to cervical factors ("history-indicated cerclage"); however, studies have shown no evidence of effectiveness of history-indicated prophylactic cerclage in preventing preterm birth versus no cerclage. ${ }^{10}$ With the possibility of measuring cervical length on TVUS, the practice of providing cerclage to women assessed to be at high risk of preterm birth due to cervical shortening has become common. A clinical trial of women at high risk for preterm delivery, that compared prophylactic cerclage versus serial ultrasound surveillance of cervical length with cerclage only if cervical changes occurred ("ultrasound- indicated cerclage"), found no significant 
difference in median gestation at delivery, number delivering $<24$ weeks, at 24-32 weeks and at 32-37 weeks. ${ }^{11}$ Moreover, the majority of high risk women (64\%) who were measured serially on TVUS did not require a cerclage placement. ${ }^{11}$ Thus, it appears that providing cerclage to high risk women on the basis of cervical changes on TVUS does not increase the incidence of preterm birth and may, in fact, reduce cerclage placement rates overall (compared to a policy of history-indicated prophylactic cerclage).

\section{Ultrasound-Indicated Cerclage vs. Conservative Management}

Though ultrasound-indicated cerclage has been shown to be equivalent to prophylactic cerclage on outcomes of preterm birth, evidence of the effectiveness of ultrasoundindicated cerclage versus more conservative treatment, such as bed rest, is not well understood. As with any intervention, cervical cerclage is not without risk, and maternal infection and pyrexia have been documented in the literature as adverse effects of the procedure. ${ }^{10}$ It is therefore crucial to delineate the effectiveness of ultrasound-indicated cervical cerclage in asymptomatic women at risk of preterm delivery versus more conservative treatment and to clarify the specific populations in which it may be beneficial.

A search was performed to identify all randomized controlled trials (RCTs) or meta-analyses examining the use of cervical cerclage versus less invasive treatment for prevention of preterm delivery in asymptomatic women demonstrating cervical changes on TVUS. The search used the following terms: "Cervical Length Measurement"[Mesh], "cervical length," "short cervix," "shortened cervix," "cervical shortening," "Cerclage, Cervical"[Mesh], "cervical stitch," "cerclage." Based on titles, 148 abstracts on PubMed were screened for inclusion. Abstracts that were selected for full-text review were any that appeared to relate cervical length on TVUS and placement of cerclage with preterm delivery. Twenty-five articles met these criteria and were selected for full-text review to assess: (a) whether they examined the use of cervical cerclage versus less invasive treatment for prevention of preterm delivery in asymptomatic women with singleton gestations demonstrating cervical changes on TVUS, and (b) whether, methodologically, they were true RCTs or meta-analyses. In total, four RCTs and two meta-analyses met these inclusion criteria. ${ }^{12-17}$

The RCTs showed conflicting results: three of the four RCTs found no statistically significant effect of cerclage versus no cerclage on outcomes of preterm birth in women with cervical shortening on TVUS. ${ }^{12,14,15}$ In contrast, although the CIPRACT trial did not directly compare rates of preterm delivery in cerclage with bed-rest versus bed-rest alone, it did demonstrate findings suggestive of reduced preterm delivery in the cerclage group. ${ }^{13}$ Specifically, CIPRACT found a statistically significant difference in the number of patients with post-interventional cervical length $>/=25 \mathrm{~mm}$, favouring the cerclage group versus bed rest alone. ${ }^{13}$ As well, of the 22 women in the trial with a post-interventional cervical length $>/=25 \mathrm{~mm}$, only one delivered before 34 weeks - significantly less frequent than women with a post-interventional cervical length $<25 \mathrm{~mm} .{ }^{13}$ These findings indirectly suggest that a significant increase in cervical length in the cerclage group versus bed rest may mediate decreased rates of preterm delivery. However, the strength of this association is weak as this trial only had a sample size of 36 participants.

In response to these contradictory results, two meta-analyses were performed on the individual patientlevel data of these four trials in order to increase sample size and more precisely demonstrate the effect of treatment with cervical cerclage for short cervix on ultrasonography versus no cerclage on the primary outcome of preterm birth $\left(<35\right.$ weeks gestation). ${ }^{16,17}$ One meta-analysis of pooled patient data $(n=607)$ found no significant benefit or detriment of cerclage versus no cerclage in asymptomatic pregnant women who were found to have a short cervical length on TVUS screening in the second trimester. ${ }^{16}$ The other meta-analysis of pooled patient data $(n=705)$ found no statistically significant effect of cerclage (performed on the basis of obstetrical history or TVUS cervical length) versus no cerclage on outcomes of preterm birth at cutoffs between 16 and 27 weeks. ${ }^{17}$ Moreover, logistic regression models demonstrated that the use of cervical length as an indication for cerclage did not have a statistically significant effect on preterm birth. ${ }^{17}$

Though these meta-analyses did not demonstrate any benefit of ultrasound-indicated cerclage in their overall population, subgroup analyses revealed particular groups of women wherein cerclage conferred statistically significant benefit or detriment compared to no cerclage. In particular, all singleton gestations grouped together and more noteably the subgroups of singleton gestations with a prior preterm birth and singleton gestations with prior second-trimester loss showed a significant reduction in preterm birth in cerclage versus no cerclage. ${ }^{16}$ Moreover, a subgroup analyses of women with multiple gestations demonstrated that cerclage was associated with a significantly higher incidence of preterm birth $<35$ weeks. ${ }^{16}$ It therefore seems probable that there are particular groups, such as singleton gestations with prior preterm birth (at 16-36 weeks gestation) and prior second-trimester loss (birth at 16-23 weeks), in which cervical cerclage for short cervix on TVUS is particularly effective in preventing preterm birth. However, the strength of these associations must be tempered with the inherent 
statistical risk associated with making multiple comparisons in RCTs.

Recent research has been aimed at identifying those patient characteristics that may mediate benefit from therapeutic cerclage following short cervix on TVUS. These characteristics include obstetric history, cervical inflammation, preoperative cervical length and presence of visible membranes at time of cerclage. ${ }^{18-21}$ In order to assess current practice and guide future research, it is important to consider the impact of these characteristics on the effectiveness of cervical cerclage.

\section{Obstetrical History}

There is evidence that women who are considered higher risk for preterm delivery on the basis of their obstetrical history may uniquely benefit from cervical cerclage following cervical changes detected on TVUS. As stated earlier, in a meta-analysis of asymptomatic pregnant women who were found to have a short cervical length on TVUS in the second trimester, a subgroup analysis showed that cerclage significantly reduced preterm birth in women who had singleton gestations and a prior preterm birth, or singleton gestations with prior second-trimester loss. Preterm birth was also significantly reduced by cerclage when all singleton gestations were grouped together; however, reductions in preterm birth within the subgroup of singleton gestations with no risks for preterm birth was not statistically significant. ${ }^{16}$ Thus, the effectiveness of cervical cerclage may be attenuated in singleton gestations without high risk features such as prior preterm birth and prior second-trimester loss. Indeed, in a case-control study of 67 low-risk women (no history of prior preterm birth or mid-trimester loss) with singleton gestations and an incidental finding of cervical length $</=25 \mathrm{~mm}$ on TVUS, therapeutic cerclage showed no improvement on rate of delivery $<35$ weeks compared to rest alone, even after controlling for confounders such as baseline gestational age and cervical length. ${ }^{19}$ This is consistent with an RCT that demonstrated no benefit of therapeutic cerclage placement for cervical length $<=15 \mathrm{~mm}$ found incidentally in population of low-risk women with singleton gestations. ${ }^{15}$ It appears that even screening the general obstetric population using transvaginal ultrasound is unlikely to be helpful, as a cohort study of the general population of singleton pregnant women found that cervical length measurement of $<=30 \mathrm{~mm}$ had a positive predictive value of only $4.5 \%$ for preterm birth. ${ }^{22}$

It appears that in singleton gestations, ultrasoundindicated cervical cerclage may be more efficacious in those women with a higher risk obstetrical features such as prior preterm delivery or prior second-trimester loss. Future research should focus on this subgroup of women in order to increase sample sizes and demonstrate treatment effect with better precision.

\section{Cervical Inflammation}

It has been proposed that amniotic-chorionic inflammation may be an initiating factor in a cascade of events that results in preterm birth. ${ }^{23}$ There is evidence that the combined occurrence of increased IL- 8 concentrations in cervical mucous and a short cervix is associated with a high likelihood of microbial invasion of the amniotic cavity and chorioamnionitis. ${ }^{24}$ Evidence has also shown a relationship between high IL-8 concentrations in cervical mucous and premature delivery in asymptomatic pregnant women generally at low risk. ${ }^{25}$ Moreover, a relationship has been demonstrated between increased levels of amniotic fluid inflammatory cytokines and cervical length $<5 \mathrm{~mm}$, even in the absence of infection or labour. ${ }^{26}$ Thus, there seems to be a common association between shortened cervix, cervical inflammation, chorioamnionitis and preterm delivery.

A retrospective study of 16,508 relatively low-risk singleton pregnancies was performed in order to investigate the efficacy of cerclage in patients with cervical shortening $(<25 \mathrm{~mm})$ at 20 to 24 weeks, with and without elevated cervical IL-8, in preventing preterm delivery before 37 weeks. ${ }^{20}$ Overall, the risk of preterm delivery did not differ between those receiving and not receiving cerclage. However, in a subgroup of patients with short cervix and normal cervical mucous IL-8 concentrations, those receiving cerclage were less likely to have a preterm delivery $(<37$ weeks). ${ }^{20}$ In contrast, among patients with a short cervix and high cervical mucous IL-8 concentrations, those receiving cerclage were significantly more likely to have a preterm delivery $\left(<37\right.$ weeks). ${ }^{20}$ This suggests that cervical cerclage may be effective in those patients with short cervix on TVUS and without cervical inflammation, whereas it may be harmful in those patients with evidence of cervical inflammation. ${ }^{20}$ Three of the four aforementioned RCTs administered pericerclage antibiotics, which may have attenuated any effect that cervical inflammation may have had on the efficacy of cerclage in those populations..$^{12,13,15}$ However, one RCT examining women with high risk factors for preterm birth with short cervix $<25 \mathrm{~mm}$ administered pericerclage antibiotics only at the discretion of the treating obstetrician. ${ }^{14}$ This study also found no significant benefit of cerclage on preterm birth even though it enrolled a higher risk population that might have been more likely to benefit from cerclage. ${ }^{14}$ Women in this study who did not receive pericerclage antibiotics may have been at higher risk of cervical inflammation, and this may have attenuated the effectiveness of cerclage on preventing preterm delivery in this population. 
It appears that ultrasound-indicated cerclage may be efficacious in women without evidence of cervical inflammation. This effect may be mediated by the fact that both cervical inflammation and short cervix may be linked to the presence of chorioamnionitis, and chorioamnionitis may be an initiating event in the cascade of events leading to preterm birth. Thus, future trials should focus on determining the effectiveness of ultrasound-indicated cerclage in women without evidence of cervical inflammation.

\section{Preoperative Cervical Length and Presence of Visible Membranes at Time of Cerclage}

There is evidence that presence of visible fetal membranes at time of cerclage may impact on its effectiveness in preventing preterm birth. A literature review that included data for 638 women who presented with a dilated external cervical os and bulging or "hour-glassing" membranes on physical examination (articles examining women with cervical incompetence diagnosed on ultrasound were excluded) found that emergency cerclage prolonged pregnancy an average of seven weeks plus one day. ${ }^{27}$ However, a prospective observational study of women at high risk of premature delivery that specifically examined ultrasound-indicated cerclage to prevent preterm delivery found contrasting results. ${ }^{21}$ The study examined how preoperative cervical length and visibility of fetal membranes at the time of suture insertion impacted on the effectiveness of ultrasound-indicated cerclage, and found that gestational age at delivery was significantly worse in those women with visible membranes at the time of surgery than for women with no visible membranes, regardless of preoperative cervical length. ${ }^{21}$ However, in this population, visible fetal membranes occurred exclusively in women with preoperative cervical lengths of $</=15 \mathrm{~mm} \cdot{ }^{21}$ Thus, women with visible fetal membranes at the time of suture may represent a very high risk group who are destined for a worse outcome regardless of placement of cerclage and visible membranes may be more prevalent with cervical lengths of of $</=15 \mathrm{~mm}^{21}$

Three of the four RCTs excluded patients on the basis of bulging membranes or cervical dilatation, albeit to different degrees. ${ }^{12,13,15}$ Rust et al. included patients with prolapse of membranes into the endocervical canal, but excluded patients with membranes prolapsed beyond the external os. ${ }^{12}$ Similarly, Althuisius et al. excluded patients that showed membranes bulging into the vagina, ${ }^{13}$ while To et al. excluded patients with dilated cervix at the time of screening. ${ }^{15}$ In contrast, Berghella et al. explicitly stated that advanced cervical dilatation or membrane bulging in the vagina was not an exclusion criteria. ${ }^{14}$ One woman in the cerclage group had a cervix $4 \mathrm{~cm}$ dilated and did not receive cerclage, while two women in the no-cerclage group received rescue cerclage after later detection of dilatation of the cervix by manual examination. ${ }^{14}$ Again, this study found no significant benefit of cerclage on preterm birth even though it enrolled a higher risk population that might have been more likely to benefit from cerclage. It is possible that those patients with cervical dilatation or membrane bulging in the vagina are destined for a worse prognosis. Though incidence of cervical dilatation seemed to be distributed equally between the groups, there were no data presented on the incidence of membrane bulging in the vagina in cerclage versus no cerclage groups. Any differences between the groups may have diluted the cerclage treatment effect.

It appears that ultrasound-indicated cerclage may not be efficacious in those women with presence of visible membranes at time of suture insertion and that visible membranes may be more prevalent in those patients with cervical length $<=15 \mathrm{~mm}$. Future controlled trials should focus on identifying those women with visible membranes at time of suture insertion as well as those women with cervical length $</=15 \mathrm{~mm}$ in order to clarify their impact on the effectiveness of ultrasound-indicated cerclage in preventing preterm birth.

\section{Implications for Research and Clinical Practice}

A Cochrane review on cerclage and pregnancy loss published in 2003 concluded that the "use of a cervical stitch should not be offered to women at low or medium risk of mid trimester loss, regardless of cervical length by ultrasound. The role of cervical cerclage for women who have short cervix on ultrasound remains uncertain as the numbers of randomized women are too few to draw firm conclusions." ${ }^{28}$ This review examined meta-analyses that included RCTs published after 2003, and despite the increased number of randomized women, the meta-analyses continue to demonstrate that there is no benefit of cerclage over more conservative management following short cervix on TVUS in low-risk pregnant women. ${ }^{16,17}$ Further research has identified that obstetrical history, evidence of cervical inflammation, preoperative cervical length and visible fetal membranes at time of cerclage placement are important features that may modify the effectiveness of ultrasoundindicated cerclage in preventing preterm birth in singleton gestations. However, despite this informative research, it remains difficult to objectively assess the effectiveness of an intervention once it has already been adopted into clinical practice. Moreover, in an area of practice where significant uncertainty remains, one must always consider the potential for harm caused by the intervention as well as additional costs to the medical system. Thus, as research moves forward, it will be important for carefully designed RCTs to examine the aforementioned characteristics a priori, in order to define a group of women in whom cervical cerclage is 
optimally effective in preventing preterm birth and wherein the benefits of cerclage outweigh adverse effects of the procedure. It will also be important to examine current clinical practice in order to clarify indications for cerclage placement and determine whether management practices are congruent with best evidence.

\section{REFERENCES}

1. McCormick MC. The contribution of low birth weight to infant mortality and childhood morbidity. N Engl J Med 1985;312:82-90.

2. Hamilton BE, Martin JA and Ventura SJ. "Births: preliminary data for 2005." Health E-Stats. 2006. <http://www.cdc.gov/nchs/products/pubs/pubd/hestats/ prelimbirths05/prelimbirths05.htm> (14 February 2009)

3. Goldenberg RL and Rouse DJ. The prevention of premature birth. N Engl J Med 1998;339:313-320.

4. Goldenberg RL, Culhane JF, Iams JD, Romero R. Epidemiology and causes of preterm birth. Lancet 2008;371(9606):75-84.

5. Berghella $\mathrm{V}$. Novel developments on cervical length screening and progesterone for preventing preterm birth. BJOG 2009;116(2):182-187.

6. Pramod R, Okun N, McKay D, Kiehn L, Hewson S, Ross S, Hannah ME. Cerclage for the short cervix demonstrated by transvaginal ultrasound: current practice and opinion. J Obstet Gynaecol Can 2004;26(6):564-70.

7. Berghella V, Roman A, Daskalakis C, Ness A, Baxter JK. Gestational age at cervical length measurement and incidence of preterm birth. Obstetrics \& Gynecology 2007;110(2):311-317.

8. Crane JMG, Hutchens D. Transvaginal sonographic measurement of cervical length to predict preterm birth in asymptomatic women at increased risk: a systematic review. Ultrasound Obstet Gynecol 2008;31:579-587.

9. Althuisius AM, Dekker GA. A five century evolution of cervical incompetence as a clinical entity. Current Pharmaceutical Design 2005;11(6):687-697.

10. Drakeley AJ, Roberts D, Alferivic Z. Cervical cerclage for the prevention of preterm delivery: meta-analysis of randomized trials. Obstet Gynecol 2003;102(3):621-7.

11. Groom KM, Bennett PR, Golara M, Thalon A, Shennan AH. Elective cervical cerclage versus serial ultrasound surveillance of cervical length in a population at high risk for preterm delivery. European Journal of Obstetrics \& Gynecology and Reproductive Biology 2004;112:158-161.

12. Rust OA, Atlas RO, Reed J, van Gaalen J, Balducci J. Revisiting the short cervix detected by transvaginal ultrasound in the second trimester: why cerclage therapy may not help. Am J Obstet Gynecol 2001;185:1098-1105.

13. Althuisius S, Dekker G, Hummel P, Bekedam D, Kuik D, Van Geijn H. Cervical incompetence prevention randomized cerclage trial (CIPRACT): effect of therapeutic cerclage with bed rest vs. bed red only on cervical length. Ultrasound Obstet Gynecol 2002;20:163-167.

14. Berghella V, Odibo A, Tolosa JE. Cerclage for prevention of preterm birth in women with a short cervix found on transvaginal ultrasound examination: a randomized trial. American Journal of Obstetrics and Gynecology 2004;191:1311-1317.

15. To MS, Alferivic Z, Heath VCF, Cicero S, Cacho AM, Williamson PR, Nicolaides KH. Cervical cerclage for the prevention of preterm delivery in women with short cervix: randomised controlled trial. Lancet 2004;363: 184953.

16. Berghella V, Odibo AO, To MS, Rust OA, Althuisius SM. Cerclage for short cervix on ultrasonography: meta-analysis of trials using individual patient-level data. Obstetrics and Gynecology 2005;106(1):181-189.

17. Jorgensen A, Alfirevic Z, Smith CT, Williamson PR; on behalf of the cerclage IPD Meta-analysis Group. Cervical stitch (cerclage) for preventing pregnancy loss: individual patient data meta-analysis. BJOG 2007;114:1460-1476.

18. Poggi SH, Vyas N, Pezzullo JC, Landy HJ, Ghidini A. Therapeutic cerclage may be more efficacious in women who develop cervical insufficiency after a term delivery. Am J Obstet Gynecol 2009;200:68.e1-68.e3.

19. Incerti M, Ghidini A, Locatelli A, Poggi S, Pezzullo JC. Cervical length $<=25$ $\mathrm{mm}$ in low-risk women: a case control study of cerclage with rest versus rest alone. Am J Obstet Gynecol 2007;197:315.e1-315.e4.

20. Sakai M, Shiozaki A, Tabata M, Sasaki Y, Yoneda S, Arai T, Kato K, Yamakawa Y, Saito S. Evaluation of effectiveness of prophylactic cerclage of a short cervix according to interleukin-8 in cervical mucus. Am J Obstet Gynecol 2006;194(1):14-19.

21. Groom KM, Shennan AH, Bennett PR. Ultrasound-indicated cervical cerclage: outcomes depends on preoperative cervical length and presence of visible membranes at time of cerclage. Am J Obstet Gynecol 2002;187:445-449.

22. Davies G, Ottenhof C, Woodman M, Farley A, Julien N, Van Vugt D, Day A. Cervical length and relaxin as predictors of preterm birth. JOGC 2008;30(12):1124-1131.

23. Lockwood CJ, Kuczynski E. Markers of risk for preterm delivery. Journal of Perinatal Medicine 1999;27(1):5-20.

24. Rizzo G, Capponi A, Vlachopoulou A, Angelini E, Grassi C, Romanini C. Ultrasonographic assessment of the uterine cervix and interleukin- 8 concentrations in cervical secretions predict intrauterine infection in patients with preterm labor and intact membranes. Ultrasound Obstet Gynecol 1998;12:86-92.

25. Sakai M, Sasaki Y, Yoneda S, Kasahara T, Arai T, Okada M, Hosokawa H, Kato $\mathrm{K}$, Soeda Y, Saito S. Elevated interleukin-8 in cervical mucus as an indicator for treatment to prevent premature birth and preterm, pre-labor rupture of membranes: a prospective study. Am J Reprod Immunol 2004;51:220-225.

26. Kiefer DG, Keeler SM, Rust OA, Wayock CP, Vintzileos AM, Hanna N. Is midtrimester short cervix a sign of intraamniotic inflammation? American Journal of Obstetrics and Gynecology 2009; 200(4):374.e1-374.e5.

27. Cockwell HA, Smith GN. Cervical incompetence and the role of emergency cerclage. JOGC 2005;27(2):123-129.

28. Drakeley AJ, Roberts D, Alfirevic Z. Cervical stitch (cerclage) for preventing pregnancy loss in women. Cochrane Database of Systematic Reviews 2003; Issue 1. Art. No.: CD003253. DOI: 10.1002/14651858.CD003253. 

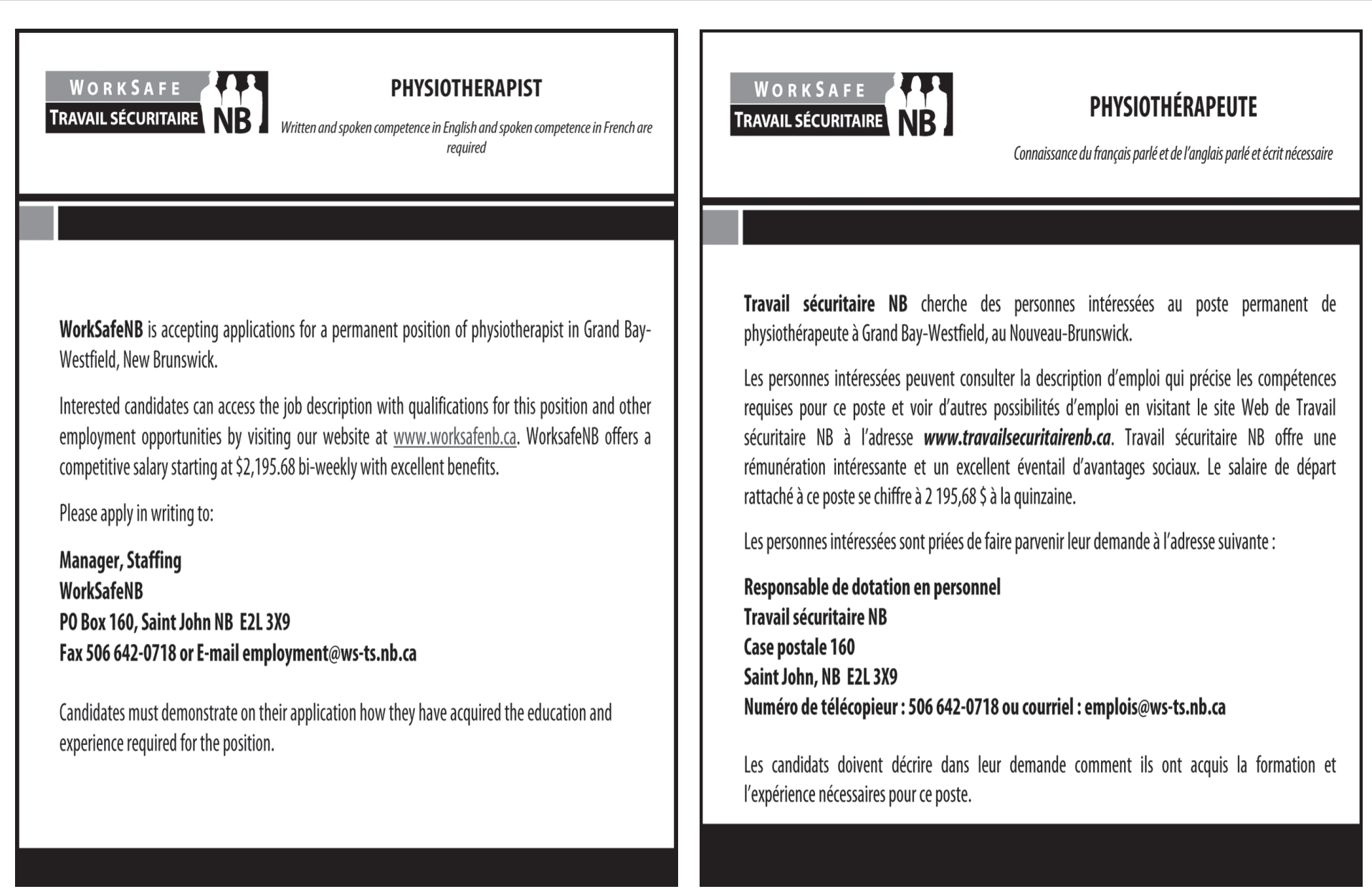

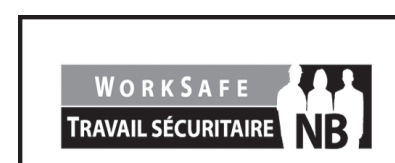

Written and spoken competence in English and French is required

WorkSafeNB is accepting applications for a permanent position of physician in Grand Bay-Westfield, New Brunswick.

Interested candidates can access the job description with qualifications for this position and other employment opportunities by visiting our website at www.worksafenb.ca. WorkSafeNB offers a very attractive compensation package, which includes an equitable salary with excellent benefits, and no weekend or evening work.

This competition will remain open until a suitable candidate is found. Please apply in writing to:

\section{Manager, Staffing \\ WorkSafeNB}

PO Box 160, Saint John NB E2L 3X9

Fax 506 642-0718 or E-mail employment@ws-ts.nb.ca

Candidates must demonstrate on their application how they have acquired the education and experience required for the position.
Travail sécuritaire NB cherche des personnes intéressées au poste permanent de physiotherapeute à Grand Bay-Westfield, au Nouveau-Brunswick.

Les personnes intéressées peuvent consulter la description d'emploi qui précise les compétences requises pour ce poste et voir d'autres possibilités d'emploi en visitant le site Web de Travail sécuritaire NB à l'adresse www.travailsecuritairenb.ca. Travail sécuritaire NB offre une émunération intéressante et un excellent éventail d'avantages sociaux. Le salaire de départ es personnes intéressées sont priées de faire parvenir leur demande à l'adresse suivante:

Responsable de dotation en personnel

Travail sécuritaire NB

Case postale 160

Saint John, NB E2L 3X9

Numéro de télécopieur : $506642-0718$ ou courriel : emplois@ws-ts.nb.ca

Les candidats doivent décrire dans leur demande comment ils ont acquis la formation et l'expérience nécessaires pour ce poste.

\section{WOR KSAFE TRAVAIL SÉCURITAIRE}

\section{MÉDECIN}

Connaissance du français et de l'anglais parlés et écrits nécessaire
Travail sécuritaire NB cherche des personnes intéressées au poste permanent de médecin à Grand Bay-Westfield, au NouveauBrunswick.

Les personnes intéressées peuvent consulter la description d'emploi qui précise les compétences requises pour ce poste et voir d'autres possibilités d'emploi en visitant le site Web de Travail sécuritaire NB au www.travailsecuritairenb.ca. Travail sécuritaire NB offre une rémunération équitable et d'excellents avantages sociaux. De plus, la personne choisie n'aura pas à travailler les fins de semaine ni les soirs.

Le concours restera ouvert jusqu'à ce qu'on recrute un-e candidat-e qui convient. Les personnes intéressées sont priées de faire parvenir leur demande à l'adresse suivante :

\author{
Responsable de dotation en personnel \\ Travail sécuritaire NB \\ Case postale 160 \\ Saint John, NB E2L 3X9 \\ Numéro de télécopieur : 506 642-0718 ou courriel : \\ emplois@ws-ts.nb.ca
}

Les candidats doivent décrire dans leur demande comment ils ont acquis la formation et l'expérience nécessaires pour le poste. 